\title{
Feasibility of ReproSystem in Indonesia
}

\author{
Sudraji Sumapraja ${ }^{*}$, Vincent L. Pisacane ${ }^{\dagger}$, Stephen P. Yanek ${ }^{\dagger}$, Robert L. Stewart ${ }^{\dagger}$, James R. Champion ${ }^{\dagger}$
}

The success of ReproSystem in a country is dependent not only on the viability of each component but also on the infrastructure of the country in which it will be used. In addition to the hardware and software required to use each component, the country must have a telecommunication system which will allow for the proper functioning of ReproSystem. The following paper focuses on the feasibility of using the existing Indonesian telecommunications system for MomCare. Because MomCare is the most complicated of the components, if the telecommunications system is adequate for its support, it will aslo support the other ReproSystem components.

\section{TELEMEDICINE}

Telemedicine, which literally means medicine at a distance, is a term that refers to the delivery of health care by combining medical knowledge with local and long distance communication services. Telemedicine has been in place since the advent of the radio and telephone. It has proven effective in limited and unique situations, typically the delivery of health care and education and training in remote locations. Aspects of reproductive health care, which can be achieved by means of telemedicine include observation, diagnosis, treatment, education and training and documentation. Most recently, telemedicine has incorporated capabilities or functions made possible by innovations in computer technology. In addition, advances in Indonesian and global communication connectivity have positioned telemedicine as a viable and vital means for augmenting clinical medicine and education and training, particularly in remote locations.

The appeal of telemedicine is fueled by several interests of the Government of Indonesia: first, the desire

\footnotetext{
* Expert staff for Minister of Research and Technology/ University of Indonesia, Jakarta, Indonesia

† Applied Physics Laboratory, The Johns Hopkins University, Baltimore, $M D, U S A$
}

to provide health care to those who presently have need, but limited access; second, the desire to reduce the cost of health care to those who now have access; third, the desire to provide quality care by transferring knowledge from experienced clinicians to service providers when and as needed; and, fourth, the desire to reduce unnecessary travel and duplication of services, These interests, when combined with recent advances in computer and communications technology and the national telecommunications infrastructure, portend a significant role for a telemedicine system known as MomCare in delivering maternal health care in particular, and quality health care and health education in general.

\section{TELECOMMUNICATIONS}

Indonesia's accomplishments in telecommunications are impressive. The rate of long-distance telephone call completion inmproved from $19 \%$ to $36 \%$ during 1988 to 1994 . The number of lines in service experienced an average annual growth rate of about $19 \%$, and investment increased from US $\$ 340$ million to about $\$ 1$ billion. ${ }^{1}$

\section{Local Telephone Network}

The Government has an ambitious plan to improve the nation's telephone density to 1.6 per 100 population by the end of PELITA V (1994), and to 3.7 per 100 population by the end of PELITA VI (1999). This will be accomplished by installing 5 million lines during PELITA VI as well as PABX systems, inter-exchange transmission and network management apparatus, central digit switches, and switch manufacturing and assembly systems. Furthermore, the introduction of wireless systems will overcome complexities of constructing underground cable networks. ${ }^{1}$

\section{Long Distance Network}

The Indonesian long distance network consists of two primary components: terrestrial and satellite. The terres- 
trial network is based on microwave radio and coaxial cable and fiber optic cables. The primary carrier is the microwave system, which stretches from Aceh in Sumatra to Ujung Pandang in Sulawesi, and includes Java and Nusa Tenggara. The network also includes a new fiber optic cable between Jakarta and Surabaya, and a submarine cable between Surabaya and Banjarmasin. A second fiber optic cable will be installed between Jakarta and Surabaya. To improve services to Kalimantan and Sulawesi, submarine cables will be installed between Surabaya, Banjarmasin, and Ujung Pandang; and Pangkalpinang and Pontianak.

The satellite transmission system consists of the Bgeneration of Palapa satellites and 216 earth stations. Two new C-generation satellites are scheduled to be commisssioned in 1995 and 1996. Each will be equipped with 34 transponders, 10 more than the Bgeneration satellites. ${ }^{1}$

\section{International Network}

INDOSAT is the primary provider of international telecommunications services, which includes telephone, telex, telegram, packet switched data, store and forward facsimile.

Gateways in Jakarta, Medan, Surabaya and Batam provide more than 3,770 circuits. International direct dialing can be made to 209 destinations throughout the world. ${ }^{1}$

\section{Nonvoice and Other Facilities}

Packet-Switched Data Network (PSDN), which is provided by Lintasarta, provides a digital data network service at speeds up to $64 \mathrm{kbps}$, a dial-up service, leased line service and a VSAT network service. The PSDN service is available via dial-up at 300 and 1,200 bps, and dedicated or leased lines at 300, 1,200 and $4,800 \mathrm{bps}$. Leased line service can move data locally at 2,400 bps, and over longer distances at 1,200 bps. These services are available in Jakarta, Surabaya, Bandung, Semarang, Yogyakarta, Denpasar, Medan, Palembang, Batam and Ujung Pandang. PSDN is also connected through facilities of INDOSAT to exchange data with approximately 116 other public packet switched data networks in 49 countries.

\section{Mobile Radio Services-Cellular}

The Global Systems for Mobile Communications (GSM) entered the Indonesian market about 2 years ago. It not only acts as a digital cellular telephone and a replacement for the analog cellular telephone, but also as a device for transfer of digital voice, data and images. Exchange of multimedia data can thus be achieved by way of radio wave or microwave frequencies.

GSM technology is more efficient in its use of the frequency spectrum and provides for greater capacity compared with cellular analog technology. A GSM phone can communicate with a nother GSM phone via one or more transceivers, each transceiver working within a specific radius, generally 5 to 10 kilometers. It also will enable connections to facilities such as Asynchronous Transfer Mode (ATM) and Integrated Services Digital Network (ISDN). There are currently about 1 million GSM subscribers in Indonesia.,

\section{Radio Trunking}

There are presently three nationwide private mobile radio trunking service providers in Indonesia, using systems built by Philips, Nokia and Motorola. They received provisional licences for pilot projects in 1992. Permanent licenses are expected to be issued before the end of $1995 .^{1}$

\section{TELEMEDICINE AND MOMCARE}

The acceptance of telemedicine for delivery of health care depends on the timely exchange of multimedia data. MomCare, a computer-based system that extends reproductive health care expertise, allow experts at referral centers to work with clinicians at remote sites, using real-time transfer of video, voice images and computer files.

Transmission rates for telemedicine have been traditionally driven by a desire for extremely high quality images for radiology and pathology, for full-motion video, and for the ability to carry out sophisticated processing at locations with computers. Reproductive health care, unlike radiology and pathology, does not require extremely high quality images or full-motion video to be effective.

Video conferencing, still or slow motion image transfer, electronic mail, text dialogue, white boarding and file transfer are functions of MomCare that make telemedicine effective for reproductive health care. Those functions are well within the range of capabilities of desktop computers and client-server digital processors. Those capabilities continue to increase dramatically as costs simultaneously decrease.

The advent of the Pentium and Power PC microprocessor chips and faster and cheaper random access and magnetic memories have increased processor operating speed to $100 \mathrm{Mbps}$. Their use, however, for mul- 
timedia applications combining audio, still images, conferencing and full-motion video increases demand for more transmission bandwith, or, in other words, wideband telecommunications services.

\section{THE STATUS OF TELEMEDICINE AND TELE- COMMUNICATIONS}

Affordable wideband telecommunications are becoming a global reality because of:

- proliferation of optical fiber transmission; advances in high-speed hardware including digital electronic, electronic optical and optical integrated circuits;

- international agreements on standards;

- proliferation of wireless systems;

- improved data compression techniques; and

- development of intelligent software.

Similarly, Indonesia is enroute toward achieving affordable wideband services.

Relatively inexpensive optical fiber cable is rapidly replacing copper as the primary transmission medium between fixed sites. Advantages of optical fiber cable transmission systems include: higher transmission bandwidths, lower impedance to light waves allowing for longer distances between repeaters, no cross-talk between fibers, lower transmission errors, improved security since taping is more difficult, lower mass and volume, lower cost, lower power requirements, higher flexibility for easier installation and decreased sensitivity to environmental effects such as lightning and storms.

Two types of optical fiber cables are in use: multimode and single mode. Multi-mode optical fiber cable is cheaper to install, but is limited in transmission rates to less than $155 \mathrm{Mbps}$, and distances between nodes of less than $2 \mathrm{~km}$. Consequently it is primarily used for local area networks. Single mode optical fiber cable, although more expensive because of associated electronics, call carry data over longer distances between nodes, up to $50 \mathrm{~km}$, and at higher rates, approaching $400 \mathrm{Gbps}$ in laboratory tests. Optical amplifiers being developed will increase this distance significantly.

Digital transmission using the Integrated Services Digital Network (ISDN) has a standard interface consisting of a basic rate with dual $64 \mathrm{kbps}$ voice/data channels and a T1 transmission primary rate with capability of $1.544 \mathrm{Mbps}$. This transmission rate is insufficient for the transfer of high quality full-motion video, since, for instance, VHS quality video requires about 1.2 Mbps and High Definition TeleVision (HDTV) up to $50 \mathrm{Mbps}$.

Wireless communication is important for fixed sites not wired for telephone service, and mobile sites or individuals. Use of cellular circuits has grown and will continue to grow exponentially, but will ultimately be limited by the bandwidth available.

Communications satellites provide service to multiple users in a region and to users in remote locations. Satellite service is attractive in less developed areas without a terrestrial telecommunication infrastructure (including cellular) and for mobile populations. There are currently just under 200 communication satellites in synchronous orbit with announced plans to launch up to an additional thousand. Depending on the size of the receiving antenna, satelite transmission can be up to $10 \mathrm{Mbps}$.

Very Small Aperture Terminals (VSAT) that work with existing satellite constellations are available that are less than half a meter in size. Several additional satellite personal communications systems are under development to provide global communications with handheld units. These systems include the Inmarsat-P, Loral and Qualcomm's GLOBALSTAR, Microsoft's Teledesic, Motorola's Iridium and TRW's Odyssey. Selected service is expected to be available as early as 1997.

Currently some telemedicine networks use High Frequency (HF) communications links. Considerations such as cost, terrain and low look angles to available satellites may make it worth while to use HF at selected locations in telemedicine networks: Cost considerations, for example, could dictate using HF as the primary means of communication when voice communications and lower data rates are sufficient, switching to more expensive satellite links only when high quality, full-motion video is essential or when a global link is required which can best be established through satellite resources. Application of modern data compression techniques to HF systems would allow transfer of image data faster than the ordinary slow-scan video associated with the HF media in the past.

State-of-the-art HF systems currently achieve data rates up to $2400 \mathrm{bps}$, automatically select the optimum frequency, and perform error correction on digital data. In addition to passing information using ionospheric propagation, HF ground wave can be used to achieve high quality, non-fading links over short distances over short ranges (up to $50 \mathrm{~km}$ ). The special advantage of using HF ground wave is that reliable and repeatable communications links can be established over nonline-of-sight paths. 
Wide area networks are the interconnections between geographically distributed communication nodes and include dial-up analog and digital transmission over the Public Switched Telephone Network (PSTN) and digital transmission over shared or dedicated leased lines. Plain Old Telephone Service (POTS) is capable of line rates of between $9.6 \mathrm{kbps}$ and $28.8 \mathrm{kbps}$ over existing analog networks.

It is unlikely that future telecommunications systems will ever provide sufficient transmission rates for some users. However, even with the availability of wide bandwidths, it should be recognized that the ability to effectively use lower bandwidths will provide that user with an advantage. Consequently, data compression techniques will continue to be important in reducing transmission delays and providing a cost advantage. Data compression factors of 10 to 20 are achievable in many cases today. In some cases, especially when background information is not changing, even higher compression ratios are possible. This remains a fruitful area of research.

\section{HISTORY OF MOMCARE}

A system of inexpensive telemedicine workstations has been demonstrated by The Johns Hopkins University in 1995 to provide effective medical care for the United States Navy. The workstations were the precursor to MomCare. The demonstration system used existing computer hardware and software technology, and standard landline and cellular telephone hook-ups and COMSAT's Inmarsat communications satellites at a nominal rate of about $14.4 \mathrm{kbps}$.

The purposes of the demonstrations were, first, to provide physicians and paramedics in the field opportunities to obtain consultation, and, second, to determine the requirements for a more capable, operational telemedicine system. Preliminary experiments in which physicians at Johns Hopkins University and elsewhere provided diagnostic and treatment consultation as well as surgical consultation including realtime laparoscopic surgery were judged to be quite successful.

\section{FEASIBILITY OF MOMCARE FOR INDONESIA}

MomCare offers a cost effective way to expand the availability of life-saving services which can reduce maternal and infant mortality, and lessen dependence upon costly transport systems. In addition, it simultaneously opens a new avenue for "just-in- time-train- ing and mentoring" of service providers in the use of important new skills.

MomCare can operate in Indonesia using the existing and planned telecommunications infrastructure. In fact, it will be a value-added application for the infrastructure, capitalizing on past, present and future investment to extend clinical care and education and training to as many people in the nation within reach of a telephone and electricity as possible.

MomCare is feasible because a critical design objective was to derive optimal medical, education and training benefit while using existing telecommunications systems within Indonesia without modification. The system uses an "open architecture" approach, which means that the design for Indonesia will:

- be adapted to reproductive health needs and ease of operation;

- require low maintenance;

- will interconnect with other MomCare units over existing and planned telecommunications systems; and

- have modular replaceable hardware and software that can be upgraded, as needed.

There are clear indications that dramatic changes have already occured in Indonesia in the transfer of information, and in building the information transfer infrastructure. The information age is upon us in reproductive health care as it is in other fields of medicine, education and human services. It is my belief that the real question about the future of MomCare is not whether or not it is here to stay, but rather the extent and the speed to which we will exploit the technology to serve the health care needs of our women and families.

\section{REFERENCES}

1. Document of the World Bank, Report No. 13874-IND, "Staff Appraisal Report, Indonesia, Telecommunications Sector Modernization Project," 18 May 1995.

2. GSM. Heading Towards Universal Personal Telecommunications. Globalink 1995; 1(1):20-3.

3. Indonesia enters ISDN era. Jakarta Post 9 September 1995.

4. Long M. 1992/1993. The World Satellite Almanac, 3rd Edition.

5. Inmarsat. No Longer Just an Inter-Ship Telephone Facility. Globalink 1995; 1(1):42. 